Int. J. Dev. Biol. 51: 463-472 (2007)

doi: $10.1387 /$ ijdb.072320to

\title{
The first steps towards hearing: mechanisms of otic placode induction
}

\author{
TAKAHIRO OHYAMA, ANDREW K. GROVES* and KAREEN MARTIN \\ Department of Cell and Molecular Biology, House Ear Institute, Los Angeles, CA, USA
}

\begin{abstract}
The entire inner ear, together with the neurons that innervate it, derive from a simple piece of ectoderm on the side of the embryonic head - the otic placode. In this review, we describe the current state of the field of otic placode induction. Several lines of evidence suggest that all craniofacial sensory organs, including the inner ear, derive from a common "pre-placodal region" early in development. We review data showing that assumption of a pre-placodal cell state correlates with the competence of embryonic ectoderm to respond to otic placode inducing signals, such as members of the fibroblast growth factor (FGF) family. We also review evidence for FGF-independent signals that contribute to the induction of the otic placode. Finally, we review recent evidence suggesting that Wnt signals may act after FGF signaling to mediate a cell fate decision between otic placode and epidermis.
\end{abstract}

KEY WORDS: FGF, Wnt, otic placode, ear development, induction

The formation of the otic placode is the earliest morphologically visible event in inner ear development. It is a simple layer of thickened ectoderm lying next to the hindbrain and yet this nondescript patch of skin will give rise to one of the most complex sensory organs in the body, producing cells such as mechanosensory hair cells and the neurons of the vestibuloacoustic ganglion which transmit hearing and balance information to the brain. The development of such a sophisticated structure from simple origins involves a series of changes in the otic ectoderm, which are the results of consecutive inductive signals emanating from neighboring tissues and within the ear itself. Inner ear formation thus provides an excellent model to study principles of embryonic induction.

The otic placode becomes visible after the events of gastrulation have laid down the body plan of the vertebrate embryo, typically once the first 5-10 pairs of somites have been generated. The placode then invaginates to produce a vesicle, the otocyst, which will develop into the different components of the inner ear: the cochlea, the semicircular canals and their associated sensory organs - the cristae - and the sensory maculae of the utricle and saccule, together with the vestibulo-acoustic ganglion. Although otic placode induction has been studied from the end of the $19^{\text {th }}$ century, early studies relied on morphological evidence of ear formation such as the formation of an otic vesicle or sensory organs, which necessarily come after the molecular and genetic signaling events that initiate induction. The emergence of molecular biology and genetics has enabled a more precise dissection of this process using molecular markers associated with ear tissue and has provided candidate inducers involved in otic induction. The ability to manipulate the embryo and assay the expression of specific otic markers has revealed multiple inductive steps in otic placode induction. In this review we provide a model where three major steps punctuate the induction of the otic placode. The first step is the formation of a region of competence for all craniofacial sensory placodes - the so-called "pre-placodal domain". The second step is the induction of a "pre-otic field" within this preplacodal domain, which is subsequently refined into the otic placode and surrounding non-otic epidermis in a third inductive step.

\section{Evidence for a pre-placodal domain}

All craniofacial sensory organs (nose, lens, ear, trigeminal and epibranchial ganglia and lateral line) arise from placodal structures located at the periphery of the neural plate (reviewed in Baker and Bronner-Fraser, 2001; Brugmann and Moody, 2005). There is growing evidence supporting the idea that these placodes derive from a common pre-placodal domain consisting of a narrow band of ectoderm that encompasses the anterior neural plate that is established at the end of gastrulation (Baker and Bronner-Fraser, 2001, Streit, 2004, Brugmann and Moody, 2005,

Abbreviations used in this paper: FGF, fibroblast growth factor; GFP, green fluorescent protein; HB, hindbrain; OV, otic vesicle 


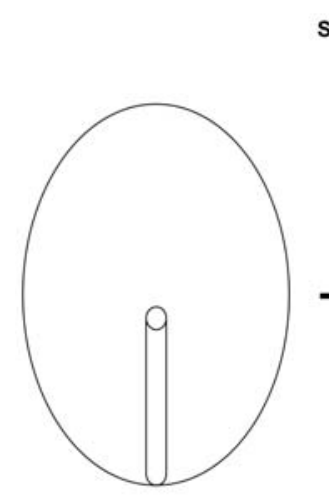

Gastrula stage embryo
STEP 1

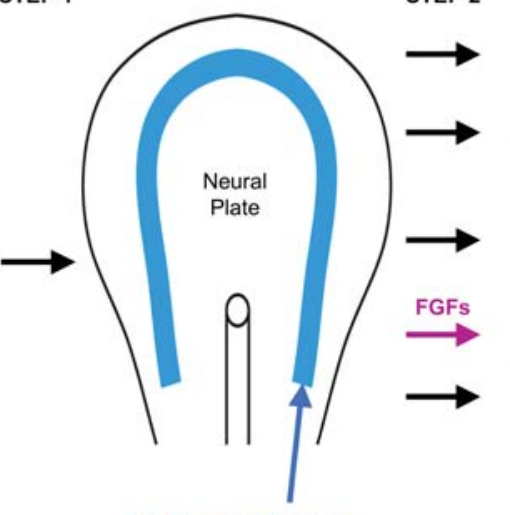

Pan Placodal Domain

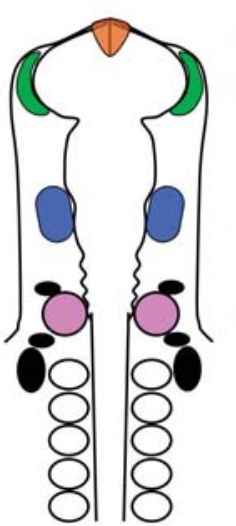

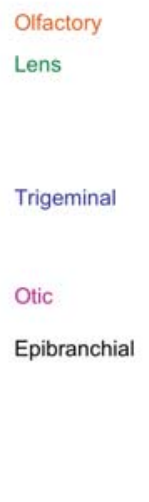

Fig. 1. The Two-Step model of placode induction. (Step1) A general placodal state (panplacodal domain) is induced in an ectodermal domain surrounding the neural ectoderm (see accompanying article by Streit in this issue). (Step 2) Different craniofacial placodes are induced in response to specific molecular signals. In the case of the otic placode, some of the inducing signals come from members of the fibroblast growth factors (FGFs).
Bailey and Streit, 2006). Current hypotheses of craniofacial development suggest that cranial placodes form in two steps. The first step is the acquisition of a general placodal state in the ectodermal domain adjacent to the neural ectoderm, with the second step being the determination of the identity of each placode by local inducing signals (Fig. 1). Streit and colleagues discuss the patterning of the pre-placodal domain in an accompanying article in this issue. Below, we briefly describe evidence for the existence of the pre-placodal domain.

Morphological evidence: Morphological studies in mice, humans and some fish and amphibian species have shown the presence of a thickened continuous band of ectoderm running along the boundary of the anterior neural plate where the future placodes will lie (Platt, 1896, Knouff, 1935, van Oostrom and Verwoerd, 1972, Verwoerd and van Oostrom, 1979, O'Rahilly and Muller, 1985, Braun, 1996, Miyake et al., 1997). This thickening becomes restricted to the different placodes as they differentiate. However, thickening of the entire pre-placodal ectoderm does not seem to be a universal feature, since it is not observed in species such as in chick and zebrafish (Baker and Bronner-Fraser, 2001, Streit, 2004).

Experimental evidence: Experimental evidence for a preplacodal domain comes from embryological studies performed in amphibians by Jacobson in the 1960s (reviewed in Jacobson, 1966). They involved the rotation of a band of ectoderm lying next to the anterior neural plate along the anteroposterior axis (Jacobson, 1963). When the rotations were conducted at open neural plate stages, the nasal, lens and otic placodes formed at the right location, suggesting that the rotated ectoderm was competent at early stages to form multiple placodes. However, when the rotations were conducted at later stages, placodes formed in inappropriate locations, suggesting they had already committed to specific placodal fates. More recently, fate map studies in fish and chick showed that precursor cells for different placodes often overlap initially before converging to their final destination and differentiating (Kozlowski et al., 1997, Whitlock and Westerfield, 2000, Streit, 2002, Bhattacharyya et al., 2004). Recent work on lens development demonstrated that the pre-placodal domain may be transiently specified to give lens tissue with later, local signals such as FGFs restricting the lens tissue to its specific location, as well as inducing the olfactory placode (Bailey et al., 2006).

Molecular evidence: Gene expression studies have shown that the pre-placodal domain can be visualized as a distinct molecular entity characterized by a number of genes belonging to the DIx, Six, Eya, Iro, BMP, Foxi and Msx families (Glavic et al., 2004, Ohyama and Groves, 2004a, Streit, 2004, Brown et al., 2005). Loss and gain of function of some of these genes resulted in the widening or reduction of the pre-placodal field (Brugmann et al., 2004, Glavic et al., 2004, Litsiou et al., 2005); this was also associated with expansion or inhibition of the expression domain of some placode-specific genes (Glavic et al., 2004). It remains to be determined which of these gene families are either necessary or sufficient for the formation of individual placodes.

\section{Otic placode induction}

Three main questions need to be addressed as a prerequisite to studying the induction of the otic placode: which tissues are competent to give rise to the otic placode and when does the induction start and finish?

\section{Genes expressed in the presumptive otic ectoderm}

In order to answer the three questions above, it is necessary to have a panel of genes marking the otic region. Several genes have been found to be specifically expressed in the region that will eventually thicken to form the otic placode. The earliest ear marker reported so far is foxi1 in zebrafish (Solomon et al., 2003). However, none of the mouse or chick Foxi class genes are expressed early in the otic placode (Ohyama and Groves, 2004a; A. Groves, unpublished observations), although mouse Foxi3 marks the entire pre-placodal domain at slightly earlier stages. The second earliest molecular marker known is Pax8 which is expressed in the presumptive otic ectoderm in fish, frogs and mice (Pfeffer et al., 1998, Heller and Brandli, 1999, Ohyama and Groves, 2004b). Pax2 expression follows shortly after, although its domain is initially larger than the otic placode in chick and mouse (Nornes et al., 1990, Krauss et al., 1991, Groves and Bronner-Fraser, 2000) A number of signaling molecules (FGFs, BMP7) and transcription factors (Eya1, GATA3, Nkx5.1, Gbx2, Sox3, Sox9) are also expressed in the otic ectoderm prior to invagination (George etal., 1994, RinkwitzBrandt et al., 1995, Wright et al., 1995, Penzel et al., 1997, Shamim and Mason, 1998, Sahly et al., 1999, Sheng and Stern, 1999, Solloway and Robertson, 1999, Wood and Episkopou, 
1999, Xu et al., 1999, Groves and Bronner-Fraser, 2000, Liu and Joyner, 2001, Sanchez-Calderon et al., 2002).

The roles of several genes expressed during otic induction have been examined in genetic studies in zebrafish. Disruption of foxi1 in the mutant hearsay resulted in severe defects or absence of otic placode formation (Solomon et al., 2003). The otic expression of early markers, pax8, pax $2 a$ and $d l \times 3 b$ was also reduced or absent in foxi1 mutants (Nissen et al., 2003, Solomon et al., 2003). Knockout mice for Foxi1 have been produced and, in contrast to fish, did not show defects in the early formation of the otic placode, although later ear development is abnormal (Hulander et al., 1998, Hulander et al., 2003). The zebrafish genes $d l \times 3 b$ and $d l \times 4 b$ are expressed in presumptive otic ectoderm shortly after foxi1 but before pax2a. Their involvement in otic placode formation was first shown in b380 mutants, containing a large chromosomal deletion which removes several genes including dl $\times 3 \mathrm{~b}$, dlx4b and sox9a (Liu et al., 2003). b380 mutants completely lack otic vesicles (Solomon and Fritz, 2002). Morpholino knockdown of both dlx3b and $\mathrm{dl} \times 4 \mathrm{~b}$ showed a milder phenotype than the b380 mutant, with serious defects in otocyst formation as well as a lack of pax2a expression (Solomon and Fritz. 2002). Targeting of dlx3b, $\mathrm{dl} \times 4 \mathrm{~b}$ and sox9a resulted in the complete loss of otic tissue, reproducing the phenotype observed in the b380 mutant (Liu et al., 2003). Unlike foxi1 mutants, morpholino knockdowns of $\mathrm{dl} \times 3 \mathrm{~b}$ and dlx4b still expressed pax8. Taken together, these results suggest a model where foxi1 would be involved in the induction of pax 8 while $d l \times 3 b$ and $d l \times 4 b$ would act later in the induction of pax2 (Hans et al., 2004, Solomon et al., 2004). Loss of either pax8 or pax 2 in fish as well as in mouse did not affect the induction of the otic placode (Torres et al., 1996, Mansouri et al., 1998, Riley et al., 1999, Whitfield et al., 2002, Hans et al., 2004). In contrast, pax2a mutants treated with pax8 morpholinos failed to form an otic placode (Hans et al., 2004, Mackereth et al., 2005), suggesting that their functions, at least in fish, are redundant. No double mutants for Pax 2 and Pax 8 have been described in mouse. The growing body of work on the interactions between the foxi $1, \mathrm{dl} \times 3 \mathrm{~b}, \mathrm{dl} \times 4 \mathrm{~b}$, pax 2 and pax8 in zebrafish has been summarized by Solomon and colleagues (Solomon et al., 2004), Riley and Phillips (Riley and Phillips, 2003) and Hans and colleagues (Hans et al., 2004). However, further experiments need to be conducted to determine whether this network of transcription factor interactions also applies to other species.

\section{Which tissues are competent to respond to otic inducing signals?}

The competence of a tissue is defined by its ability to acquire a specific fate in response to appropriate inducing signals. A simple embryological test is to graft tissue taken from different locations into the region that would normally become an otic placode and test whether the graft can develop placode characteristics. In chick, the ectoderm lying along the neural plate of the head and anterior trunk is competent to express ear specific markers and to form an otic vesicle when transplanted to the future otic placode site (Groves and Bronner-Fraser, 2000). This competence was seen in embryonic ectoderm from the end of gastrulation and decreases with age until the chick has 10-12 pairs of somites, after which time the ectoderm becomes refractory to otic inducing signals. Similar results have been seen in amphibian embryos (Gallagher et al., 1996).

\section{When is ectoderm specified to form the otic placode?}

A tissue is said to be specified when it has already received inducing signals and can express otic markers in the absence of any additional signals. The specification of otic tissue is thus an operational definition for the start of inner ear induction. In chick, specification assays for the expression of the otic markers Pax2 and BMP7 have been carried out (Groves and Bronner-Fraser, 2000). In such experiments, pieces of presumptive otic ectoderm were collected at different ages and placed in culture in minimal medium in the absence of inducing signals such as growth factors or serum. Presumptive otic ectoderm is specified to express Pax2 at the 5-6 somite stage (ss) and BMP7 at 7-8ss. Specification of Pax2 and BMP7 occurs at the approximately same time as they appear in vivo, 5ss and 7ss respectively. These experiments can give us an approximate estimate of the onset of otic placode induction, although it is important to note that other as yet unidentified genes in chick may be induced prior to Pax2.

\section{When is ectoderm committed to form the otic placode?}

A tissue is said to be committed to a particular fate when it adopts that fate regardless of its environment. A test for otic commitment is to transplant pieces of presumptive otic ectoderm
A

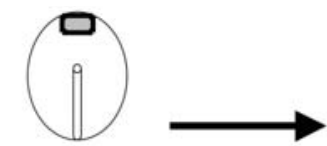

$\mathrm{HH} 3+-4$

chick embryo

Anterior epiblast

\section{B}

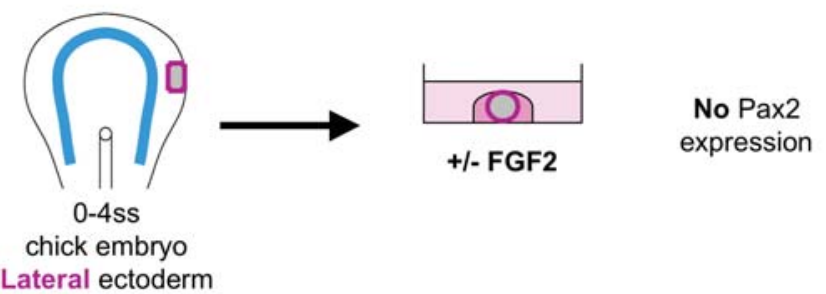

C

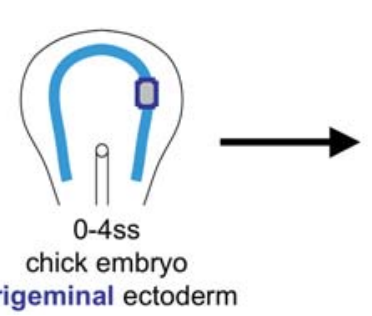

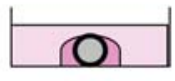

+/- FGF2
No Pax2 expression
Lateral ectoderm

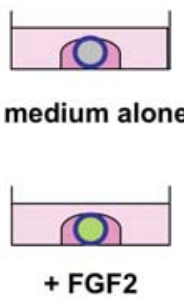

Fig. 2. Only the ectoderm within the pre-placodal region can induce Pax2 in response to FGF2. (A) Anterior epiblast from HH stage 3+-4 chick embryos is unable to induce Pax2 when cultured in presence of FGF2. (B) Lateral ectoderm (outside the pre-placodal domain) from 0-4ss chick embryos does not express Pax2 when treated with FGF2. (C) Presumptive trigeminal ectoderm (within the pre-placodal domain) from 0-4ss chick embryo expresses Pax2 only when cultured in the presence of FGF2.
No Pax2 expression medium alone

Pax2 expression

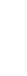




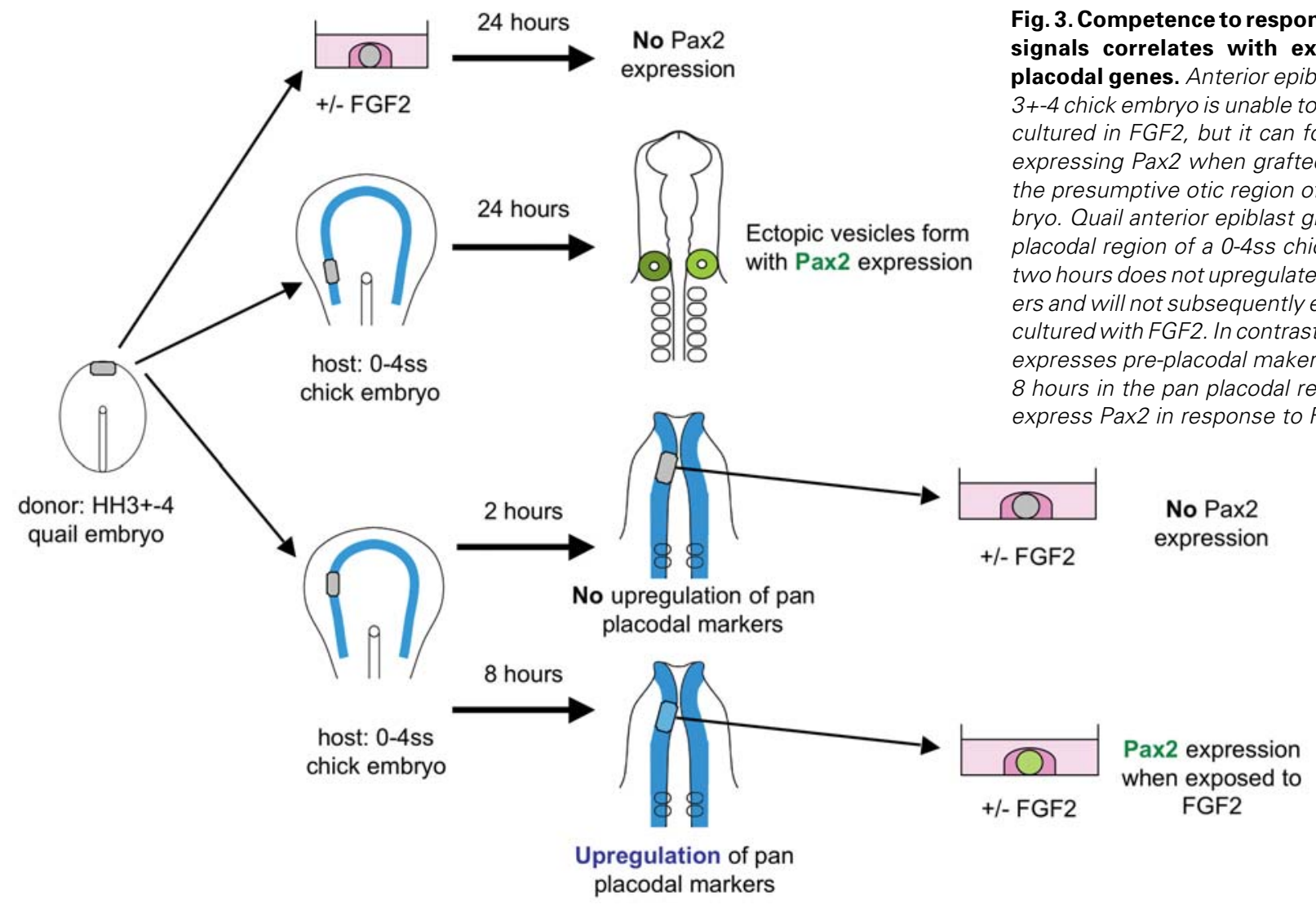

of different ages in an ectopic environment and assaying for the formation of ectopic expression of ear markers or formation of otic vesicles. These assays operationally define the end of otic placode induction. In the chick, otic ectoderm becomes committed to express Pax2 and to form a vesicle at 9-10ss (Groves and BronnerFraser, 2000). Studies in amphibians exhibited a variation in the onset of commitment from species to species (Ginsburgt, 1995). It is important to note that, as for specification, the time at which a tissue is said to become committed is dependent on the markers used and can only be considered a provisional indicator, as one can never be truly sure that the committed tissue has been challenged with all possible signals.

\section{Which tissues have otic inducing properties?}

Embryonic induction has been described as "an interaction between an inducing and responding tissue that alters the path of differentiation of the responding tissue" (Gurdon, 1987, Jacobson and Sater, 1988). Once a responding tissue has been characterized by the sorts of experiments described above, the inducing tissues remain to be identified. There is now clear evidence for the contribution of the hindbrain and mesoderm in otic placode induction. The first investigations on their potential role date from the first half of the $20^{\text {th }}$ century, although most of these experiments were performed when molecular markers were not yet available and relied on the formation of a morphologically defined structure as an indication of induction. The identification of molecular markers for the otic placode, together with genetic gain and loss of function approaches has provided more information regarding the specific roles of hindbrain and mesoderm in ear induction. For example, some zebrafish mutants have been characterized with defects in mesoderm development, namely cyclops and one-eyed pinhead (oep) mutants (Zhang et al., 1998, Gritsman et al., 1999). These fish exhibit a delayed formation of the otic vesicle. However, as these mutants present a number of other phenotypes that could also affect ear formation, it is difficult to attribute the delayed induction as solely to the lack of mesoderm. Introduction of an oepspecific morpholino in zebrafish embryos also results in smaller otic vesicles (Phillips et al., 2001, Leger and Brand, 2002). The fact that an otic vesicle still forms in the absence of mesoderm suggests that this tissue is not necessary for otic induction in fish. More recently, the role of the mesoderm in chick otic placode induction was investigated using ablation and grafting experiments. Removal of the cranial paraxial mesoderm underlying the presumptive otic ectoderm or its replacement with mesoderm from more anterior or posterior locations prevents the induction of the otic placode (Kil et al., 2005). This study also tested the role of the hindbrain in otic induction using vitamin A-deficient embryos which lack rhombomeres 5 and 6 and possess an enlarged rhombomere 4. Otic vesicles form normally in these embryos suggesting that the posterior hindbrain is not necessary for otic placode induction in birds. Mutant fish with defective hindbrain have been described, such as the valentino mutation which affects the development of rhombomere 5 and 6 , or mutants of $\mathrm{Pbx} 2$ and 4 , in which the hindbrain adopts a rhombomere 1 identity (Waskiewicz et al., 2002). Otic vesicles still form in both these mutants, although subsequent ear development is abnormal (Kwak et al., 2002). The hindbrain therefore does not appear to be necessary for the formation of an otic vesicle, however it may be necessary for later 
aspects of ear patterning. For example, in chick, the Lmx1 transcription factor requires signals from the hindbrain to be expressed, although the role of $L m \times 1$ in ear formation is still unknown (Giraldez, 1998). Finally, it has been shown that the endoderm was also involved in inner ear induction in birds (Ladher et al., 2005). Endoderm ablation resulted in the loss of epithelial thickening on the ablated side as well as the loss of Pax2 expression. In this case, it seems that the role of the endoderm is indirect with the endoderm acting on the mesoderm, which then induces ear development directly. Taken together, these data suggest that both mesoderm and the hindbrain are involved in the development of the otic placode, although their specific roles appear to vary from one species to another.

\section{What are the molecular inducers of the otic placode?}

Members of the fibroblast growth factors have been shown to play a critical role in inner ear induction in several species. Their expression in the developing hindbrain adjacent to presumptive otic tissue, or in the underlying mesoderm suggested a role for FGF family members as possible ear inducers. FGF signaling has now been demonstrated to be necessary for otic placode induction in fish, chick and mouse. In zebrafish, treatment with the FGF receptor inhibitor SU5402 resulted in the complete loss of otic vesicles as well as the loss of expression of some ear markers, pax2a and dlx3b (Leger and Brand, 2002, Maroon et al., 2002). In the chick, future ear ectoderm failed to express Pax2 and EphA4 when cultured in presence of SU5402 (Martin and Groves, 2006). In fish, fgf3 and fgf8 have been implicated as being the main candidates for FGF-dependent ear inductive signaling. Both are expressed in the vicinity of the pre-otic domain at the time of placode induction (Reifers et al., 1998, Furthauer et al., 2001, Phillips et al., 2001, Maroon et al., 2002). Loss of fgf3 or fgf8 in morpholino-treated or mutant fish was associated with a decreased expression domain of pax $2 a$ and $d \mathrm{l} \times 3 \mathrm{~b}$ as well as smaller vesicles. When both fgf 3 and fgf 8 were targeted, no otic vesicles form (Phillips et al., 2001, Leger and Brand, 2002, Maroon et al., 2002, Liu et al., 2003). In mouse, FGF3 and FGF10 are considered as potential inducers, with FGF3 being expressed in rhombomere 5 and 6 of the hindbrain and FGF10 in the mesoderm underlying the presumptive placode (Mahmood et al., 1995, McKay et al., 1996, Wright and Mansour, 2003). FGF10 mutant mice develop smaller otic vesicles (Ohuchi et al., 2000), whereas FGF3 mutants develop an otic placode, although later ear differentiation is highly abnormal (Mansour et al., 1993). Mutants of both FGF3 and FGF10 failed to form otic vesicles or form microvesicles and $\mathrm{Pax} 2$ was absent in the ear tissue, while Pax8 and Gbx2 were reduced (Alvarez et al., 2003, Wright and Mansour, 2003). FGF8 is also involved in placode induction in chick and mouse, although its role appears to be indirect. It is expressed in cranial endoderm and is necessary for the mesodermal expression of FGF19 in chick and FGF10 in mouse (Ladher et al., 2005).

The studies described above have established the central role of FGF signaling in otic placode induction in every species examined, although the identity and source of the inducing FGFs vary from species to species. It is important to note, however, that some aspects of otic placode induction are FGF-independent. For example, in zebrafish induction of foxi1, dlx4 and sox9b are unaffected in mutants lacking both fgf3 and fgf8 (Solomon et al., 2004). Indeed, foxi1 has been proposed to act as a competence factor in fish, allowing ectoderm to respond to FGF signaling, but not itself responding to FGFs (Hans et al., 2004, Hans etal., 2007), although Phillips and colleagues have shown that fgf8 mis-expression induced ectopic domains of expression of foxi1 (Phillips et al., 2004). In addition, zebrafish $\mathrm{dl} \times 3 \mathrm{~b}$ has also been reported to be FGF-independent in some studies but not others (Leger and Brand, 2002, Maroon et al., 2002, Liu et al., 2003, Solomon et al., 2004). The factors responsible for the expression of foxi1, dlx3b, dlx4b and sox9a are not known, although it has been recently suggested that BMP signaling might be a candidate for foxi1 and dlx3b induction (Hans et al., 2007). Evidence for FGF-independent pathways in otic placode induction has also come from work in chick, where induction of two otic markers, DIx3 and BMP7, was unaffected by treatment with the FGF receptor inhibitor SU5402 (Martin and Groves, 2006)

Ectopic exposure to different members of the FGF family also confirmed their role in otic placode induction. FGF beads implanted into the posterior ectoderm of Xenopus embryos or in the vicinity of the otic tissue in chick could induce ectopic otic vesicles (Lombardo et al., 1998, Lombardo and Slack, 1998, Adamska et al., 2001). Similar results were observed in chick when FGF3 was misexpressed in non-otic tissue (Vendrell et al., 2000). Although the results obtained in frogs and chicks support the inductive properties of FGF, they do not address whether FGF3 acts directly or indirectly. It is possible that FGF signaling would induce other molecules in the neighboring tissues which themselves would be responsible for the formation of ectopic otic epithelium. For example, FGF19 induces Pax2 in competent ectoderm only when the ectoderm is co-cultured with neural tissue or when FGF19 is applied in conjunction with Wnt8c (Ladher et al., 2000). The authors drew a model of placode induction in which FGF19 would
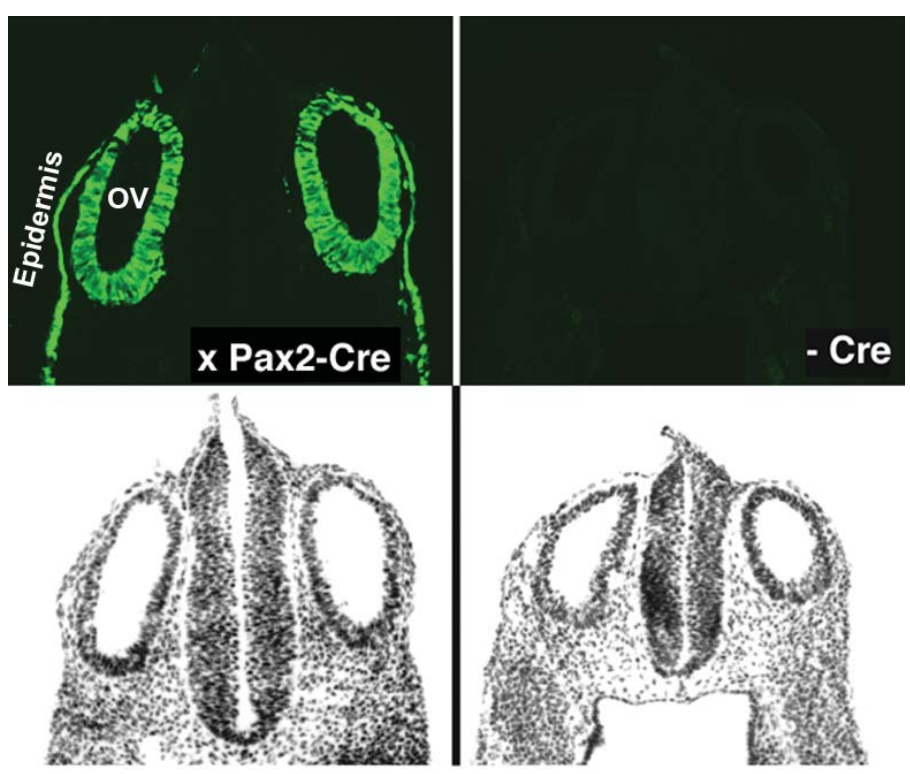

Fig. 4. Pax2 ${ }^{+}$cells give rise to both otic placode and epidermis. Pax2Cre mice are crossed with reporter mice that express GFP in a Creinducible fashion. All Pax2-expressing cells and their descendants will express GFP in embryos derived from such crosses (left). GFP-positive cells are observed not only in the otic vesicle (OV), but also in the epidermis at E9.5, while no cells are GFP-positive in reporter mice alone (right). 


\section{Normal}
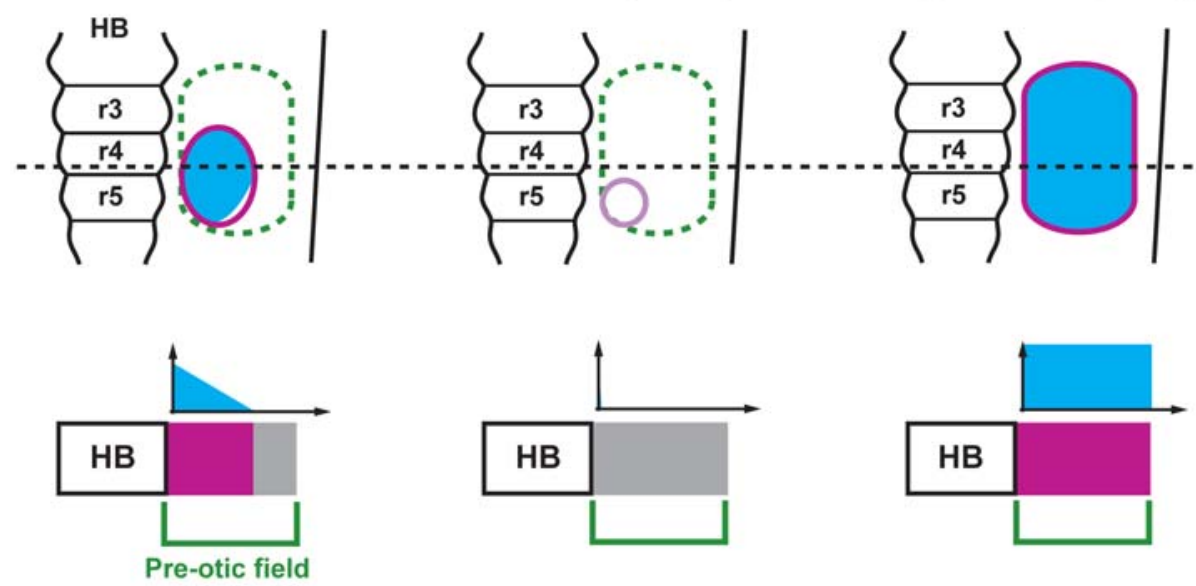

Otic placode

Epidermis

Wnt signals

Fig. 5. Wnt signals mediate a placode-epidermis fate decision. In normal mice (left), the canonical Wnt signaling pathway is activated (light blue) in the Pax $2^{+}$pre-otic field by Wnts from the hindbrain (HB). Cells receiving high levels of Wnt signals differentiate as otic placode (magenta), while those receiving lower or no Wnt signals differentiate as epidermis (grey). In the absence of Wnt signaling in the pre-otic field (center), epidermis is expanded at the expense of the otic placode. When $\beta$-catenin is stabilized in the pre-otic field (right), it activates Wntresponsive genes in the entire pre-otic field, thus expanding the otic placode at the expense of epidermis. Modified from Ohyama et al., (2006).

first induce Wnt8c expression in neural ectoderm and then induce some aspects of otic placode induction together with Wnt8c. These results are discussed further later in this review. A more recent study in chick showed that pieces of competent ectoderm respond relatively quickly to FGF2 treatment (Martin and Groves, 2006). A number of otic markers, Pax2, Pax8, EphA4, DIx3, were upregulated as early as 6 hours after exposure and induction occurred without inducing neural or mesodermal markers, suggesting that FGF likely acts directly to induce otic ectoderm. Interestingly, the otic marker BMP7 was never induced at any concentrations of FGF tested, again demonstrating the existence of FGF-independent pathways of otic induction.

\section{From pre-placode to placode: testing a two step model of otic placode induction}

In the preceding sections, we have outlined evidence for the existence of a common pre-placodal domain and have suggested that local inducing signals act on restricted regions of the preplacodal domain to induce specific cranial placodes. In the case of the otic placode, FGF signaling from the hindbrain and cranial paraxial mesoderm underlying the presumptive placode is a strong candidate for an otic inducer. Induction of cranial placodes would thus occur in two steps -induction of the pre-placodal region being a necessary prerequisite to subsequent induction of specific placodes. There is some circumstantial evidence for such a two-step model of otic induction. For example, cranial ectoderm taken from within the pre-placodal region rapidly expresses otic markers when cultured with FGF2, whereas ectoderm from the same axial level but lying lateral to the pre-placodal region is unresponsive to FGF2 (Martin and Groves, 2006). Moreover, young anterior epiblast that does not express pre-placodal genes readily forms an otocyst when grafted to the presumptive otic region, but cannot express otic markers when cultured in the presence of FGF2 (Groves and Bronner-Fraser, 2000; Martin and Groves, 2006; Figures 2 and 3).

Recent experiments have tested the hypothesis that acquisition of pre-placodal identity is necessary for subsequent induction of the otic placode by FGF signaling. Naïve epiblast tissue is able to up-regulate preplacodal genes (such as Eya and Dlx gene family members) between 4 and 8 hours after being grafted into the pre-placodal region of chick embryos. Significantly, if such grafts are removed prior to their expression of pre-placodal genes, they are unresponsive to FGF signals, whereas the same grafts respond readily when challenged with FGF after they have expressed pre-placodal genes (Martin and Groves, 2006; Fig. 3). Thus, competence to respond to FGF signaling correlates with the expression of pre-placodal genes in otic induction. There are many different ways in which pre-placodal identity could confer competence to respond to FGF signals on presumptive otic ectoderm. Many of the genes known to be expressed in the pre-placodal domain are transcription factors of the DIx, Six, Eya, Dach and Foxi families (Streit, 2004, Groves, 2005) and it is possible that some of these genes act individually or in concert as "competence factors", as has been suggested for foxi and dlx3b and dlx4b in zebrafish (Hans etal., 2004, Hans etal., 2007). It is not clear whether these competence factors act downstream of FGF signaling, or whether they themselves enable FGF signaling to occur by, for example, up-regulating components of the FGF signaling pathway. In Xenopus, over-expression of Six1 resulted in the expansion of the pre-placodal field, whereas a loss of Six1 function led to a reduction of this domain (Brugmann et al., 2004). It remains to be determined whether these results can be generalized to other species and whether these or other currently unidentified transcription factors will be sufficient to confer competence to respond to FGF signaling.

\section{Revising the two-step model: insights from fate map- ping}

The simple two-step model of placode induction described above envisages ectodermal cells adjacent to the neural tube receiving signals that up-regulate pre-placodal genes as a necessary prerequisite to the induction of specific placodes by local inducing signals. However, it is clear from fate mapping studies that the precursors of different cranial placodes can be intermingled prior to their differentiation.

For example, Kozlowski and colleagues found that at $50 \%$ epiboly in zebrafish there are regions adjacent to the presumptive otic region that give rise to not only the otic vesicle but also to other sensory organs such as lens, olfactory epithelium and trigeminal ganglion (Kozlowski et al., 1997). In a second lineage study, Streit 
labeled cells in the region of the presumptive chick otic ectoderm at late gastrula and early post-gastrula stages and found that the otic placode arises from a very broad region of the epiblast and that its precursors are intermingled with cells giving rise to the epidermis, the epibranchial placodes, the central nervous system and neural crest cells (Streit, 2002). Other studies have suggested a similar intermingling of precursor cells for the lens and olfactory placodes (Whitlock and Westerfield, 2000, Bhattacharyya et al., 2004).

Although these fate mapping studies provide convincing evidence for the intermingling of different placodal precursors, they do not provide information about when individual precursors are singled out for a particular fate. More recent fate mapping evidence has shown that this selection can occur even after the expression of early placode genes. For example, although Pax 2 is commonly regarded as one of the earliest markers of the otic placode, studies in chick and mouse reveal that Pax2-expressing cells can adopt epidermal as well as otic placode fates. In Streit's lineage analysis in chick, cells in the area of the Pax2 expressing domain at early head fold stages mainly give rise to both otic placode and nonplacodal ectoderm and the $\mathrm{Pax} 2^{+}$domain is roughly divided into placodal and non-placodal territories (see Fig. 3D and E in Streit, 2002). To further test the fate of Pax2-expressing cells, we genetically labeled $\mathrm{Pax}^{+}$ectoderm in mouse and followed the descendants of these cells by using the Cre-loxP recombination system. When Pax2-Cre transgenic mice are crossed with loxP reporter mice, $\mathrm{Pax}^{+}$cells are permanently labeled with a reporter gene product by irreversible Cre-loxP recombination. In the offspring of such crosses, reporter-positive cells are located in both the otic placode and epidermis (Ohyama and Groves, 2004b), suggesting that Pax2-expressing cells are not yet committed to an otic fate, but can also give rise to epidermis.

How can we reconcile these results with the previously described observations on the role of FGF signaling in otic placode induction? As described above, several lines of evidence suggest FGF signaling is both necessary and sufficient to induce early otic marker genes such as Pax2 (Phillips et al., 2001, Leger and Brand, 2002, Maroon et al., 2002, Ladher et al., 2005, Martin and Groves, 2006). In the light of our fate mapping studies, it is clear that FGF signaling induces a region of Pax2-expressing cells that can give rise to the otic placode, but which can also differentiate as epidermis. We have described this domain marked by early otic marker genes such as Pax2 and Pax8 as a 'pre-otic field', distinct from the otic placode. Thus, our two-step model has now acquired a third step, in which FGF signaling is required for the induction of the $\mathrm{Pax}^{+}$pre-otic field, while additional signals are required to subdivide the pre-otic field into the otic placode and epidermis. Below, we describe evidence to suggest that Wnt signaling might mediate this otic placode-epidermis fate decision.

\section{Wnt signaling and the induction of the otic placode}

Ladher and colleagues reported the first evidence of the involvement of Wnt signaling in otic placode induction. They cultured presumptive chick otic ectoderm with FGF19 or Wnt8c-soaked beads. They observed stronger induction of otic marker genes such as Pax2 with FGF19 and Wnt8c than FGF19 alone. They hypothesized that Wnt8c is induced in the hindbrain by mesodermally-derived FGF19 and that it synergistically induces otic genes with FGF19 (Ladher et al., 2000). Several observations have challenged this hypothesis - for example, Wnt8 is expressed in the hindbrain of several species after Pax2 and Pax8 are induced in the presumptive otic ectoderm (Hume and Dodd, 1993, Bouillet et al., 1996, Lekven et al., 2001). Moreover, a study by Phillips and colleagues in zebrafish showed that after depletion of Wnt8 signaling with morpholino knockdown or the Wnt antagonist dickkopf (Dkk1), the otocyst still forms although its size is smaller (Phillips et al., 2004). It is possible, however, that other Wnt molecules compensate for the loss of Wnt8 function and Dkk1 expression in these experiments does not completely block Wnt signaling. Despite these contradictory observations, it is nevertheless clear that presumptive otic ectoderm is exposed to Wnt signals. TCF/LeflacZ transgenic reporter mice, which reveal activity of the canonical Wnt signaling pathway (Mohamed et al., 2004), show the reporter activity in a subset of the pre-otic field, with cells closest to the neural tube displaying high levels of reporter activity and more lateral ectoderm displaying little or no reporter activity (Ohyama et al., 2006). To test whether Wnt signaling modulates a placodeepidermis fate decision, $\beta$-catenin, a downstream molecule necessary for canonical Wnt signaling pathway was conditionally inactivated or activated in the pre-otic field using Pax2-Cre mice (Ohyama et al., 2006). In $\beta$-catenin conditional knockout mice, the otic placode is significantly reduced in size. Conversely, conditional stabilization of $\beta$-catenin results in an expansion of a placode-like thickening at the expense of non-placodal ectoderm (Fig. 5).

These results strongly suggest that canonical Wnt signaling plays a crucial role in mediating a placode-epidermis fate decision within the pre-otic field, with cells receiving high levels of Wnt signaling differentiating as otic placode, while cells receiving little or no Wnt signaling differentiating as epidermis. To date, there is no direct evidence for the role of specific Wnt family members in this placode-epidermis fate decision. In mouse, Wnt6 is expressed in posterior surface ectoderm at E7.5 (T.O. and C. Jayasena, unpublished observations). Wnt8a is expressed in rhombomere 4 at E8.0 (Bouillet et al., 1996) and little later, Wnt1 and Wnt3a start to be expressed in the dorsal neural folds (Gavin et al., 1990). Expression of other Wnt signaling components in the pre-otic field has not been investigated in detail. However, one of the Wnt receptors, frizzled-8 and a downstream transcription factor Tcf3 seem to be expressed in the anterior ectoderm at E7.5 (Lu et al., 2004, Merrill et al., 2004). The Wnt8-Tcf3 pathway mediates body axis formation (Popperl et al., 1997, Merrill et al., 2004) and unlike Lef1 or Tcf1, Tcf3 acts as a repressor (Merrill et al., 2001). Thus, similar mechanisms might modulate a placode-epidermis fate decision in the pre-otic field.

How do the Wnt and FGF signaling pathways interact to generate the otic placode? Several studies suggest a potential crosstalk between Wnt and FGF pathways. For instance, chick Sox 2 which is expressed in the epiblast (Avilion et al., 2003) has a posterior neural plate enhancer that is synergistically activated by FGFs and Wnts. The Sox 2 enhancer region contains both Lef1 binding sites and FGF-responsive elements and reporter assays have shown that Wnt-dependent activation is significantly enhanced in the presence of FGFs, while FGF alone activates the enhancer at low level (Takemoto et al., 2006). Moreover, several lines of evidence show that increased phosphorylation of GSK3 $\beta$ by FGF signaling (possibly via Akt) enhances the stabilization of $\beta$-catenin (Hashimoto et al., 2002, Holnthoner et al., 2002, Israsena et al., 
2004, Dailey et al., 2005). These results suggest that Wnt signaling can only influence the placode-epidermis fate decision in the presence of FGF signaling. It is also possible that other nondiffusible signals such as Notch signaling are important to refine the border between placode and epidermis. Martinez-Arias and colleagues have proposed a model in which Wnt signaling acts as a transcriptional noise filter (Arias and Hayward, 2006). They also showed Notch modulates Wnt signaling by regulating the activity of $\beta$-catenin (Hayward et al., 2005, Hayward et al., 2006). Moreover, in mouse epidermis, the Notch ligand Jagged1 has been shown to be a target of $\beta$-catenin (Estrach et al., 2006). Thus, crosstalk between Wnt and other signals may be necessary to define the proper size of the otic placode.

It is also possible that FGF and Wnt signaling act independently during otic placode induction. For example, our recent studies show that activation of Wnt signaling represses the epidermis-specific transcription factor Foxi2, whereas loss of Wnt signaling causes an expansion of Foxi2 expression (Ohyama et al., 2006). Wnt signaling could therefore simply be acting as a permissive factor that defines the size of the otic placode by repressing Foxi2, thus giving FGF free rein to induce otic genes in a Foxi2-negative domain. Further gain- and loss-of-function studies with both the Wnt pathway and epidermis-specific transcriptional cascades will be required to more fully understand the relationship between Wnt and FGF signaling in ear induction.

\section{From ectoderm to otic placode: three steps and more?}

The studies described above are starting to offer a more detailed description of how naïve ectoderm is induced to form specific craniofacial placodes. First, ectoderm is induced to express pre-placodal genes in response to signals from anterior mesoderm (including cardiac mesoderm) that include FGFs together with BMP and Wnt antagonists (Litsiou et al., 2005; see article by Streit and colleagues in this issue). Second, more recent evidence suggests that pre-placodal cells are all transiently specified as having lens identity (Bailey et al., 2006), with subsequent signals restricting lens identity to only a small region of the pre-placodal region. These two steps render ectoderm competent to respond to placode-inducing signals-for example, pre-placodal identity is necessary for ectoderm to respond to FGFs to induce markers of the pre-otic field such as Pax2 (Martin and Groves, 2006). This induction of a competent pre-placodal region is likely to also be required for the induction of other placodes - for example, the response to $F G F$ in nasal placode induction (Bhattacharyya et al., 2004) and to neural tube-derived factors in trigeminal placode induction (Baker et al., 1999). Finally, the $\mathrm{Pax} 2^{+}$pre-otic field is partitioned into epidermis and committed otic placode tissue through the action of Wnt signaling (Ohyama et al., 2006). An outstanding problem is to understand how similar signals are deployed at different times during the process of placode induction to produce different results. For example, FGF signaling is crucial for the induction of pre-placodal genes (Litsiou et al., 2005), but is also later required for the induction of the nasal placode (Bhattacharyya et al., 2004), the pre-otic field (Martin and Groves, 2006) and the zebrafish epibranchial placodes (Nechiporuk et al., 2005, Nechiporuk et al., 2007, Nikaido et al., 2007, Sun et al., 2007). Nevertheless, the use of molecular biology and genetics is transforming the study of otic placode induction from an embryological curiosity to give an increasingly detailed molecular description of the genesis of one of the body's most complicated sensory organs.

\section{References}

ADAMSKA, M., HERBRAND, H., ADAMSKI, M., KRUGER, M., BRAUN, T. and BOBER, E. (2001). FGFs control the patterning of the inner ear but are not able to induce the full ear program. Mech Dev109: 303-13.

ALVAREZ, Y., ALONSO, M.T., VENDRELL, V., ZELARAYAN, L.C., CHAMERO, P., THEIL, T., BOSL, M.R., KATO, S., MACONOCHIE, M., RIETHMACHER, D. et al. (2003). Requirements for FGF3 and FGF10 during inner ear formation. Development 130: 6329-38.

ARIAS, A.M. and HAYWARD, P. (2006). Filtering transcriptional noise during development: concepts and mechanisms. Nat Rev Genet 7: 34-44.

AVILION, A.A., NICOLIS, S.K., PEVNY, L.H., PEREZ, L., VIVIAN, N. and LOVELLBADGE, R. (2003). Multipotent cell lineages in early mouse development depend on SOX2 function. Genes Dev 17: 126-40.

BAILEY, A.P., BHATTACHARYYA, S., BRONNER-FRASER, M. and STREIT, A. (2006). Lens specification is the ground state of all sensory placodes, from which FGF promotes olfactory identity. Dev Cel/11: 505-17.

BAILEY, A.P. and STREIT, A. (2006). Sensory organs: making and breaking the pre-placodal region. Curr Top Dev Bio/72: 167-204.

BAKER, C.V. and BRONNER-FRASER, M. (2001). Vertebrate cranial placodes I. Embryonic induction. Dev Bio/232: 1-61.

BAKER, C.V., STARK, M.R., MARCELLE, C. and BRONNER-FRASER, M. (1999). Competence, specification and induction of $\mathrm{Pax}-3$ in the trigeminal placode. Development 126: 147-56.

BHATTACHARYYA, S., BAILEY, A.P., BRONNER-FRASER, M. and STREIT, A. (2004). Segregation of lens and olfactory precursors from a common territory: cell sorting and reciprocity of DIx5 and Pax6 expression. Dev Bio/271: 403-14.

BOUILLET, P., OULAD-ABDELGHANI, M., WARD, S.J., BRONNER, S., CHAMBON, $P$. and DOLLE, P. (1996). A new mouse member of the Wnt gene family, mWnt8 , is expressed during early embryogenesis and is ectopically induced by retinoic acid. Mech Dev 58: 141-52.

BRAUN, C.B. (1996). The sensory biology of the living jawless fishes: a phylogenetic assessment. Brain Behav Evo/48: 262-76.

BROWN, S.T., WANG, J. and GROVES, A.K. (2005). DIx gene expression during chick inner ear development. J Comp Neuro/483: 48-65.

BRUGMANN, S.A. and MOODY, S.A. (2005). Induction and specification of the vertebrate ectodermal placodes: precursors of the cranial sensory organs. Biol Cel/97: 303-19.

BRUGMANN, S.A., PANDUR, P.D., KENYON, K.L., PIGNONI, F. and MOODY, S.A. (2004). Six1 promotes a placodal fate within the lateral neurogenic ectoderm by functioning as both a transcriptional activator and repressor. Development 131: 5871-81.

DAILEY, L., AMBROSETTI, D., MANSUKHANI, A. and BASILICO, C. (2005). Mechanisms underlying differential responses to FGF signaling. Cytokine Growth Factor Rev 16: 233-47.

ESTRACH, S., AMBLER, C.A., LO CELSO, C., HOZUMI, K. and WATT, F.M. (2006). Jagged 1 is a beta-catenin target gene required for ectopic hair follicle formation in adult epidermis. Development 133: 4427-38.

FURTHAUER, M., REIFERS, F., BRAND, M., THISSE, B. and THISSE, C. (2001). sprouty 4 acts in vivo as a feedback-induced antagonist of FGF signaling in zebrafish. Development 128: 2175-86.

GALLAGHER, B.C., HENRY, J.J. and GRAINGER, R.M. (1996). Inductive processes leading to inner ear formation during Xenopus development. Dev Biol 175: 95-107.

GAVIN, B.J., MCMAHON, J.A. and MCMAHON, A.P. (1990). Expression of multiple novel Wnt-1/int-1-related genes during fetal and adult mouse development. Genes Dev 4: 2319-32.

GEORGE, K.M., LEONARD, M.W., ROTH, M.E., LIEUW, K.H., KIOUSSIS, D., GROSVELD, F. and ENGEL, J.D. (1994). Embryonic expression and cloning of the murine GATA-3 gene. Development 120: 2673-86.

GINSBURGT, A.S. (1995). Determination of the labyrinth in different amphibian 
species and its correlation with determination of the other ectoderm derivatives. Dev Genes Evo 204: 351-58.

GIRALDEZ, F. (1998). Regionalized organizing activity of the neural tube revealed by the regulation of Imx1 in the otic vesicle. Dev Bio/203: 189-200.

GLAVIC, A., MARIS HONORE, S., GLORIA FEIJOO, C., BASTIDAS, F., ALLENDE, M.L. and MAYOR, R. (2004). Role of BMP signaling and the homeoprotein Iroquois in the specification of the cranial placodal field. Dev Bio/272: 89-103.

GRITSMAN, K., ZHANG, J., CHENG, S., HECKSCHER, E., TALBOT, W.S. and SCHIER, A.F. (1999). The EGF-CFC protein one-eyed pinhead is essential for nodal signaling. Cel/97: 121-32.

GROVES, A.K. (2005). The induction of the otic placode in Development of the Ear. Springer-Verlag, New York.

GROVES, A.K. and BRONNER-FRASER, M. (2000). Competence, specification and commitment in otic placode induction. Development 127: 3489-99.

GURDON, J.B. (1987). Embryonic induction-molecular prospects. Development 99: 285-306.

HANS, S., CHRISTISON, J., LIU, D. and WESTERFIELD, M. (2007). Fgf-dependent otic induction requires competence provided by Foxi1 and DIx3b. BMCDev Biol7: 5.

HANS, S., LIU, D. and WESTERFIELD, M. (2004). Pax8 and Pax2a function synergistically in otic specification, downstream of the Foxi1 and DIx3b transcription factors. Development 131: 5091-102.

HASHIMOTO, M., SAGARA, Y., LANGFORD, D., EVERALL, I.P., MALLORY, M. EVERSON, A., DIGICAYLIOGLU, M. and MASLIAH, E. (2002). Fibroblast growth factor 1 regulates signaling via the glycogen synthase kinase-3beta pathway. Implications for neuroprotection. J Biol Chem 277: 32985-91.

HAYWARD, P., BALAYO, T. and MARTINEZ ARIAS, A. (2006). Notch synergizes with axin to regulate the activity of armadillo in Drosophila. Dev Dyn235: 265666.

HAYWARD, P., BRENNAN, K., SANDERS, P., BALAYO, T., DASGUPTA, R., PERRIMON, N. and MARTINEZ ARIAS, A. (2005). Notch modulates Wnt signalling by associating with Armadillo/beta-catenin and regulating its transcriptional activity. Development 132: 1819-30.

HELLER, N. and BRANDLI, A.W. (1999). Xenopus Pax-2/5/8 orthologues: novel insights into Pax gene evolution and identification of Pax-8 as the earliest marker for otic and pronephric cell lineages. Dev Genet 24: 208-19.

HOLNTHONER, W., PILLINGER, M., GROGER, M., WOLFF, K., ASHTON, A.W., ALBANESE, C., NEUMEISTER, P., PESTELL, R.G. and PETZELBAUER, P. (2002). Fibroblast growth factor-2 induces Lef/Tcf-dependent transcription in human endothelial cells. J Biol Chem 277: 45847-53.

HULANDER, M., KIERNAN, A.E., BLOMQVIST, S.R., CARLSSON, P., SAMUELSSON, E.J., JOHANSSON, B.R., STEEL, K.P. and ENERBACK, S. (2003). Lack of pendrin expression leads to deafness and expansion of the endolymphatic compartment in inner ears of Foxi1 null mutant mice. Development 130: 2013-25.

HULANDER, M., WURST, W., CARLSSON, P. and ENERBACK, S. (1998). The winged helix transcription factor Fkh10 is required for normal development of the inner ear. Nat Genet 20: 374-6.

HUME, C.R. and DODD, J. (1993). Cwnt-8C: a novel Wnt gene with a potential role in primitive streak formation and hindbrain organization. Development 119: 1147-60.

ISRASENA, N., HU, M., FU, W., KAN, L. and KESSLER, J.A. (2004). The presence of FGF2 signaling determines whether beta-catenin exerts effects on proliferation or neuronal differentiation of neural stem cells. Dev Bio/268: 220-31.

JACOBSON, A.G. (1963). The Determination And Positioning Of The Nose, Lens And Ear. lii. Effects Of Reversing The Antero-Posterior Axis Of Epidermis, Neural Plate And Neural Fold. J Exp Zoo/154: 293-303.

JACOBSON, A.G. (1966). Inductive processes in embryonic development. Science 152: $25-34$

JACOBSON, A.G. and SATER, A.K. (1988). Features of embryonic induction. Development 104: 341-59.

KIL, S.H., STREIT, A., BROWN, S.T., AGRAWAL, N., COLLAZO, A., ZILE, M.H. and GROVES, A.K. (2005). Distinct roles for hindbrain and paraxial mesoderm in the induction and patterning of the inner ear revealed by a study of vitaminA-deficient quail. Dev Bio/285: 252-71.

KNOUFF, R.A. (1935). The developmental pattern of ectodermal placodes in Rana pipiens. J Comp Neuro/62: 17-71.

KOZLOWSKI, D.J., MURAKAMI, T., HO, R.K. and WEINBERG, E.S. (1997). Regional cell movement and tissue patterning in the zebrafish embryo revealed by fate mapping with caged fluorescein. Biochem Cel/ Bio/75: 551-62.

KRAUSS, S., JOHANSEN, T., KORZH, V., MOENS, U., ERICSON, J.U. and FJOSE, A. (1991). Zebrafish pax[zf-a]: a paired box-containing gene expressed in the neural tube. EMBO J10: 3609-19.

KWAK, S.J., PHILLIPS, B.T., HECK, R. and RILEY, B.B. (2002). An expanded domain of fgf3 expression in the hindbrain of zebrafish valentino mutants results in mis-patterning of the otic vesicle. Development 129: 5279-87.

LADHER, R.K., ANAKWE, K.U., GURNEY, A.L., SCHOENWOLF, G.C. and FRANCIS-WEST, P.H. (2000). Identification of synergistic signals initiating inner ear development. Science 290: 1965-7.

LADHER, R.K., WRIGHT, T.J., MOON, A.M., MANSOUR, S.L. and SCHOENWOLF, G.C. (2005). FGF8 initiates inner ear induction in chick and mouse. Genes Dev 19: 603-13.

LEGER, S. and BRAND, M. (2002). Fgf8 and Fgf3 are required for zebrafish ear placode induction, maintenance and inner ear patterning. Mech Dev 119: 91108.

LEKVEN, A.C., THORPE, C.J., WAXMAN, J.S. and MOON, R.T. (2001). Zebrafish wnt8 encodes two wnt8 proteins on a bicistronic transcript and is required for mesoderm and neurectoderm patterning. Dev Cell1: 103-14.

LITSIOU, A., HANSON, S. and STREIT, A. (2005). A balance of FGF, BMP and WNT signalling positions the future placode territory in the head. Development 132: 4051-62.

LIU, A. and JOYNER, A.L. (2001). EN and GBX2 play essential roles downstream of FGF8 in patterning the mouse mid/hindbrain region. Development 128: 18191.

LIU, D., CHU, H., MAVES, L., YAN, Y.L., MORCOS, P.A., POSTLETHWAIT, J.H. and WESTERFIELD, M. (2003). Fgf3 and Fgf8 dependent and independent transcription factors are required for otic placode specification. Development 130: $2213-24$

LOMBARDO, A., ISAACS, H.V. and SLACK, J.M. (1998). Expression and functions of FGF-3 in Xenopus development. Int J Dev Bio/42: 1101-7.

LOMBARDO, A. and SLACK, J.M. (1998). Postgastrulation effects of fibroblast growth factor on Xenopus development. Dev Dyn 212: 75-85.

LU, C.C., ROBERTSON, E.J. and BRENNAN, J. (2004). The mouse frizzled 8 receptor is expressed in anterior organizer tissues. Gene Expr Patterns 4: 56972.

MACKERETH, M.D., KWAK, S.J., FRITZ, A. and RILEY, B.B. (2005). Zebrafish pax8 is required for otic placode induction and plays a redundant role with $\mathrm{Pax} 2$ genes in the maintenance of the otic placode. Development 132: 371-82.

MAHMOOD, R., KIEFER, P., GUTHRIE, S., DICKSON, C. and MASON, I. (1995). Multiple roles for FGF-3 during cranial neural development in the chicken. Development 121: 1399-410.

MANSOUR, S.L., GODDARD, J.M. and CAPECCHI, M.R. (1993). Mice homozygous for a targeted disruption of the proto-oncogene int-2 have developmental defects in the tail and inner ear. Development 117: 13-28.

MANSOURI, A., CHOWDHURY, K. and GRUSS, P. (1998). Follicular cells of the thyroid gland require Pax8 gene function. Nat Genet 19: 87-90.

MAROON, H., WALSHE, J., MAHMOOD, R., KIEFER, P., DICKSON, C. and MASON, I. (2002). Fgf3 and Fgf8 are required together for formation of the otic placode and vesicle. Development 129: 2099-108.

MARTIN, K. and GROVES, A.K. (2006). Competence of cranial ectoderm to respond to Fgf signaling suggests a two-step model of otic placode induction. Development 133: 877-87.

MCKAY, I.J., LEWIS, J. and LUMSDEN, A. (1996). The role of FGF-3 in early inner ear development: an analysis in normal and kreisler mutant mice. Dev Bio/174: 370-8.

MERRILL, B.J., GAT, U., DASGUPTA, R. and FUCHS, E. (2001). Tcf3 and Lef1 regulate lineage differentiation of multipotent stem cells in skin. Genes Dev15: 1688-705.

MERRILL, B.J., PASOLLI, H.A., POLAK, L., RENDL, M., GARCIA-GARCIA, M.J., ANDERSON, K.V. and FUCHS, E. (2004). Tcf3: a transcriptional regulator of axis induction in the early embryo. Development 131: 263-74. 
MIYAKE, T., VON HERBING, I.H. and HALL, B.K. (1997). Neural ectoderm, neural crest and placodes: Contribution of the otic placode to the ectodermal lining of the embryonic opercular cavity in Atlantic cod (Teleostei). J Morphology 231: 231-52.

MOHAMED, O.A., CLARKE, H.J. and DUFORT, D. (2004). Beta-catenin signaling marks the prospective site of primitive streak formation in the mouse embryo. Dev Dyn 231: 416-24.

NECHIPORUK, A., LINBO, T., POSS, K.D. and RAIBLE, D.W. (2007). Specification of epibranchial placodes in zebrafish. Development 134: 611-23.

NECHIPORUK, A., LINBO, T. and RAIBLE, D.W. (2005). Endoderm-derived Fgf3 is necessary and sufficient for inducing neurogenesis in the epibranchial placodes in zebrafish. Development 132: 3717-30.

NIKAIDO, M., DOI, K., SHIMIZU, T., HIBI, M., KIKUCHI, Y. and YAMASU, K. (2007). Initial specification of the epibranchial placode in zebrafish embryos depends on the fibroblast growth factor signal. Dev Dyn 236: 564-71.

NISSEN, R.M., YAN, J., AMSTERDAM, A., HOPKINS, N. and BURGESS, S.M. (2003). Zebrafish foxi one modulates cellular responses to Fgf signaling required for the integrity of ear and jaw patterning. Development 130: 2543-54.

NORNES, H.O., DRESSLER, G.R., KNAPIK, E.W., DEUTSCH, U. and GRUSS, P. (1990). Spatially and temporally restricted expression of Pax2 during murine neurogenesis. Development 109: 797-809.

O'RAHILLY, R. and MULLER, F. (1985). The origin of the ectodermal ring in staged human embryos of the first 5 weeks. Acta Anat (Basel) 122: 145-57.

OHUCHI, H., HORI, Y., YAMASAKI, M., HARADA, H., SEKINE, K., KATO, S. and ITOH, N. (2000). FGF10 acts as a major ligand for FGF receptor $2 \mathrm{IIlb}$ in mouse multi-organ development. Biochem Biophys Res Commun 277: 643-9.

OHYAMA, T. and GROVES, A.K. (2004a). Expression of mouse Foxi class genes in early craniofacial development. Dev Dyn 231: 640-646.

OHYAMA, T. and GROVES, A.K. (2004b). Generation of Pax2-Cre mice by modification of a Pax2 bacterial artificial chromosome. Genesis 38: 195-9.

OHYAMA, T., MOHAMED, O.A., TAKETO, M.M., DUFORT, D. and GROVES, A.K. (2006). Wnt signals mediate a fate decision between otic placode and epidermis. Development 133: 865-75.

PENZEL, R., OSCHWALD, R., CHEN, Y., TACKE, L. and GRUNZ, H. (1997). Characterization and early embryonic expression of a neural specific transcription factor XSOX3 in Xenopus laevis. Int J Dev Bio/41: 667-77.

PFEFFER, P.L., GERSTER, T., LUN, K., BRAND, M. and BUSSLINGER, M. (1998). Characterization of three novel members of the zebrafish Pax2/5/8 family: dependency of Pax5 and Pax8 expression on the Pax2.1 (noi) function. Development 125: 3063-74.

PHILLIPS, B.T., BOLDING, K. and RILEY, B.B. (2001). Zebrafish fgf3 and fgf8 encode redundant functions required for otic placode induction. Dev Bio/235: 351-65.

PHILLIPS, B.T., STORCH, E.M., LEKVEN, A.C. and RILEY, B.B. (2004). A direct role for Fgf but not Wnt in otic placode induction. Development 131: 923-31.

PLATT, J.B. (1896). Ontogenetic differentiation of the ectoderm in Necturus. $Q$. J. Microsc. Sci. 38: 485-547.

POPPERL, H., SCHMIDT, C., WILSON, V., HUME, C.R., DODD, J., KRUMLAUF, R. and BEDDINGTON, R.S. (1997). Misexpression of Cwnt8C in the mouse induces an ectopic embryonic axis and causes a truncation of the anterior neuroectoderm. Development 124: 2997-3005.

REIFERS, F., BOHLI, H., WALSH, E.C., CROSSLEY, P.H., STAINIER, D.Y. and BRAND, M. (1998). Fgf8 is mutated in zebrafish acerebellar (ace) mutants and is required for maintenance of midbrain-hindbrain boundary development and somitogenesis. Development 125: 2381-95.

RILEY, B.B., CHIANG, M., FARMER, L. and HECK, R. (1999). The deltaA gene of zebrafish mediates lateral inhibition of hair cells in the inner ear and is regulated by pax2.1. Development 126: 5669-78.

RILEY, B.B. and PHILLIPS, B.T. (2003). Ringing in the new ear: resolution of cell interactions in otic development. Dev Bio/261: 289-312.

RINKWITZ-BRANDT, S., JUSTUS, M., OLDENETTEL, I., ARNOLD, H.H. and BOBER, E. (1995). Distinct temporal expression of mouse Nkx-5.1 and Nkx-5.2 homeobox genes during brain and ear development. Mech Dev 52: 371-81.
SAHLY, I., ANDERMANN, P. and PETIT, C. (1999). The zebrafish eya1 gene and its expression pattern during embryogenesis. Dev Genes Evo/209: 399-410.

SANCHEZ-CALDERON, H., MARTIN-PARTIDO, G. and HIDALGO-SANCHEZ, M (2002). Differential expression of Otx2, Gbx2, Pax2 and Fgf8 in the developing vestibular and auditory sensory organs. Brain Res Bul/57: 321-3.

SHAMIM, H. and MASON, I. (1998). Expression of Gbx-2 during early development of the chick embryo. Mech Dev 76: 157-9.

SHENG, G. and STERN, C.D. (1999). Gata2 and Gata3: novel markers for early embryonic polarity and for non-neural ectoderm in the chick embryo. Mech Dev 87: 213-6.

SOLLOWAY, M.J. and ROBERTSON, E.J. (1999). Early embryonic lethality in Bmp5;Bmp7 double mutant mice suggests functional redundancy within the 60A subgroup. Development 126: 1753-68.

SOLOMON, K.S. and FRITZ, A. (2002). Concerted action of two dlx paralogs in sensory placode formation. Development 129: 3127-36.

SOLOMON, K.S., KUDOH, T., DAWID, I.B. and FRITZ, A. (2003). Zebrafish foxi1 mediates otic placode formation and jaw development. Development 130: 92940.

SOLOMON, K.S., KWAK, S.J. and FRITZ, A. (2004). Genetic interactions underlying otic placode induction and formation. Dev Dyn 230: 419-33.

STREIT, A. (2002). Extensive cell movements accompany formation of the otic placode. Dev Bio/249: 237-54.

STREIT, A. (2004). Early development of the cranial sensory nervous system: from a common field to individual placodes. Dev Bio/276: 1-15.

SUN, S.K., DEE, C.T., TRIPATHI, V.B., RENGIFO, A., HIRST, C.S. and SCOTTING, P.J. (2007). Epibranchial and otic placodes are induced by a common Fgf signal, but their subsequent development is independent. Dev Bio/303: 675686.

TAKEMOTO, T., UCHIKAWA, M., KAMACHI, Y. and KONDOH, H. (2006). Convergence of Wnt and FGF signals in the genesis of posterior neural plate through activation of the Sox2 enhancer N-1. Development 133: 297-306.

TORRES, M., GOMEZ-PARDO, E. and GRUSS, P. (1996). Pax2 contributes to inner ear patterning and optic nerve trajectory. Development 122: 3381-91.

VAN OOSTROM, C.G. and VERWOERD, C.D. (1972). The origin of the olfactory placode. Adv Anat Embryol Cell Bio/58: 1-75.

VENDRELL, V., CARNICERO, E., GIRALDEZ, F., ALONSO, M.T. and SCHIMMANG, T. (2000). Induction of inner ear fate by FGF3. Development 127: 2011-9.

VERWOERD, C.D. and VAN OOSTROM, C.G. (1979). Cephalic neural crest and placodes. Adv Anat Embryol Cell Bio/58: 1-75.

WASKIEWICZ, A.J., RIKHOF, H.A. and MOENS, C.B. (2002). Eliminating zebrafish pbx proteins reveals a hindbrain ground state. Dev Cel/3: 723-33.

WHITFIELD, T.T., RILEY, B.B., CHIANG, M.Y. and PHILLIPS, B. (2002). Development of the zebrafish inner ear. Dev Dyn 223: 427-58.

WHITLOCK, K.E. and WESTERFIELD, M. (2000). The olfactory placodes of the zebrafish form by convergence of cellular fields at the edge of the neural plate. Development 127: 3645-53.

WOOD, H.B. and EPISKOPOU, V. (1999). Comparative expression of the mouse Sox1, Sox2 and Sox3 genes from pre-gastrulation to early somite stages. Mech Dev 86: 197-201.

WRIGHT, E., HARGRAVE, M.R., CHRISTIANSEN, J., COOPER, L., KUN, J., EVANS, T., GANGADHARAN, U., GREENFIELD, A. and KOOPMAN, P. (1995). The Sry-related gene Sox9 is expressed during chondrogenesis in mouse embryos. Nat Genet 9: 15-20.

WRIGHT, T.J. and MANSOUR, S.L. (2003). Fgf3 and Fgf10 are required for mouse otic placode induction. Development 130: 3379-90.

XU, P.X., ADAMS, J., PETERS, H., BROWN, M.C., HEANEY, S. and MAAS, R. (1999). Eya1-deficient mice lack ears and kidneys and show abnormal apoptosis of organ primordia. Nat Genet 23: 113-7.

ZHANG, J., TALBOT, W.S. and SCHIER, A.F. (1998). Positional cloning identifies zebrafish one-eyed pinhead as a permissive EGF-related ligand required during gastrulation. Ce//92: 241-51. 


\section{Related, previously published Int. J. Dev. Biol. articles}

See our Special Issue Ear Development edited by Fernando Giraldez and Bernd Fritzsch at:

http://www.ijdb.ehu.es/web/contents. php?vol=51\&issue=6-7

Analysis of Netrin 1 receptors during inner ear development

Tanja Matilainen, Maarja Haugas, Jordan A. Kreidberg and Marjo Salminen

Int. J. Dev. Biol. (2007) 51: 409-414

Cell proliferation during the early compartmentalization of the Xenopus laevis inner ear

Quincy A. Quick and Elba E. Serrano

Int. J. Dev. Biol. (2007) 51: 201-210

Functional analysis of FGF3 during zebrafish inner ear development

$\checkmark$ Vendrell, D Gimnopoulos, T Becker, T Schimmang

Int. J. Dev. Biol. (2001) 45: S105-S106

Role of Raf kinases during inner ear development.

C Sanz, Y Leon, M Garcia-Gil and I Varela-Nieto

Int. J. Dev. Biol. (1996) 40: S83-S84

p75 and Trk oncoproteins expression is developmentally regulated in the inner ear of human embryos.

E Vazquez, I San José, J Naves, J A Vega and J Represa

Int. J. Dev. Biol. (1996) 40: S77-S78 